\title{
Didática da Educação Física escolar e o processo lógico de apreensão do saber
}

\author{
Maristela da Silva Souza*
}

\begin{abstract}
Resumo: Este texto visa situar, no contexto escolar, o conhecimento de que trata o âmbito da didática da Educação Física, demonstrando a sua relação com a lógica formal de apreensão do saber. Para a superação desta realidade, em que a Educação Física compromete-se, de maneira dominante, com uma prática de cunho competitiva, apresentamos a lógica dialética como possibilidade de apreensão, no plano do pensamento, do movimento contraditório presente na realidade social e conseqüentemente, presente na organização escolar e no desenvolvimento das práticas corporais.
\end{abstract}

Palavras-chave: Didática. Lógica. Educação Física.

\section{INTRODUÇÃO}

Nosso ponto de partida para encaminharmos uma discussão sobre Didática da Educação Física (EF) é a sua inserção no plano da produção do conhecimento científico. Essa posição se justifica por duas razões:

- a EF como área de conhecimento que trata da cultura corporal, produzida no processo histórico pelos sujeitos em movimento, portanto, resultante das manifestações sociais, entre elas, a ciência;

- a importância de entendermos a relação estabelecida entre didática da EF e ciência, consiste em compreender que em um processo de ensino, os aspectos didáticos expressam-se pelas opções científicas e pela maneira como estabelecemos a relação entre o conhecimento e a realidade.

* Professora Adjunta do Centro de Educação Física e Desportos da Universidade Federal de Santa Maria (UFSM). Coord. da Linha de Estudos Epistemológicos e Didáticos em Educação Física Escolar (LEEDEFE/CEFD/UFSM). Santa Maria, RS, Brasil. E-mail: marissouza@mail.ufsm.br. 
Por esse fato, apreender a produção e o desenvolvimento da didática da EF nos remete a aprender a ciência, compreendendo-a no processo histórico real de sua produção, estritamente relacionado às necessidades que a humanidade vai elaborando para manter, reproduzir e elevar as suas formas de existência.

Os problemas decorrentes dos processos reais da vida, sejam políticos, econômicos e culturais, são solucionados sob o contraponto de diferentes visões de mundo, que, no embate ideológico, contribuem para uma produção de conhecimento conflituosa e estabelecida pelo movimento de contraposição de diferentes saberes.

Situado nesse contexto, o campo de conhecimento da EF estabelece, na forma de interpretar a realidade, distintos paradigmas científicos com metas específicas de chegar ao conhecimento e que orientam a sua relação didática no trato com os conteúdos de ensino.

Neste diálogo teórico, a EF compromete-se, de maneira dominante, com uma prática de cunho eminentemente competitivista, que se embasa numa lógica formal de ciência. Assim, princípios como a sobrepujança e o selecionamento (KUNZ, 1994) são disseminados de maneira irrefletida e assimilados por todos como se fosse "natural" e exclusivamente desejável na EF o desenvolvimento de práticas discriminatórias.

Provém desse processo uma forte contribuição à formação de sujeitos historicamente passivos, imobilizados em suas práticas sociais, limitados à descrição do aparente das coisas e silenciados no processo de construção da cultura elaborada.

Diante das consequiências que o desenvolvimento dessa prática de EF acarreta no processo de formação do sujeito, pretendemos apresentar outra possibilidade de trato com o conhecimento, que, ao nosso ver, faz-se necessária no processo didático da EF. Possibilidade esta que venha a desenvolver os conteúdos de ensino da EF como produto da conquista de homens e mulheres, abordando-os pedagogicamente em meio ao contexto escolar e aos nexos que constituem a engrenagem das relações sociais capitalistas, pois, como nos declara Escobar (1997), na escola, o principal objetivo não é transmitir

Movimento, Porto Alegre, v. 13, n. 03, p. 181-199, setembro/dezembro de 2007. 
conhecimento para ser assimilado, mas a partir de uma determinada prática pedagógica - daí a autora utilizar os termos de Marx - reduzir o movimento visível, que só aparece no fenômeno, ao verdadeiro movimento interno.

Isso significa que, quando nossos alunos vão conhecer a realidade, e aqui, em especial, através da área da $\mathrm{EF}$, não será qualquer caminho capaz de validar esse processo, pois de nada adianta utilizarmos um ou outro processo de ensino se não temos claro a lógica de apropriação do saber que norteará a nossa ação didática. Acreditamos que no trato com o conhecimento, a relação dialeticamente estabelecida entre sociedade, ciência e ensino escolar constitui uma base fundamental para a apropriação, no plano do pensamento, da concretude dos fatos, suas relações e interconexões, a partir de que o conhecimento é constituído integradamente.

Portanto, este texto visa situar, no contexto escolar, o conhecimento de que trata o âmbito da didática da Educação Física, demonstrando o seu comprometimento com a lógica formal de apreensão do saber. Para a superação dessa realidade, apresentamos a lógica dialética como possibilidade de apreensão, no plano do pensamento, do movimento contraditório presente na realidade social e, conseqüentemente, presente na organização escolar e no desenvolvimento das práticas corporais.

\section{DIDÁTICA DA EDUCAÇÃO FíSICA E A SUA ESPECI- FICIDADE NO TRATO COM O CONHECIMENTO NO CONTEXTO ESCOLAR}

Fundamentados em Freitas (2000), podemos dizer que, ao expressar a sua Teoria Educacional, o educador expressa, também, entre outros aspectos, o seu projeto histórico, que tipo de pessoa quer formar, os fins da educação e a relação entre educação e sociedade em seu desenvolvimento. Já uma Teoria Pedagógica trata do "trabalho pedagógico", incluindo, portanto, a própria didática. Nesta direção, concordamos com Wachowicz (1989) que no contexto geral da pedagogia, a didática trata do ensino enquanto

Movimento, Porto Alegre, v. 13, n. 03, p. 181-199, setembro/dezembro de 2007. 
apropriação do saber, enquanto "ação-trabalho", que se desenvolve em uma determinada realidade, a sala de aula. No entanto, a autora não entende o confronto estabelecido na sala de aula, como algo que se desenvolve entre alguém que sabe (professor) e alguém que não sabe (aluno), mas entre estes e o saber (conteúdo), na busca de sua apropriação. Temos, então, todo um processo de abstração e de concretização a ser desenvolvido através da didática, no sentido de apreender, no plano do pensamento, o real-concreto das coisas.

Para o real desenvolvimento desse processo, entendemos que a pedagogia, especificamente através da didática, deve apresentar-se preparada para enfrentar os reflexos das propriedades e relações reais do conhecimento e da sociedade, pois como nos declara Freitas (2000), a reflexão sobre a didática não deve ser desenvolvida sem a sua contextualização dentro da organização do trabalho pedagógico da escola, que, por sua vez, relaciona-se com o trabalho material produtivo.

Não é apenas a didática que deve estar sob análise, mas sim a escola, sua organização e seus métodos, já que todos esses níveis são históricos e, portanto, mudam sob o impulso do fluxo da mesma história. (FREITAS, 2000, p. 58).

Para Freitas (2000), a organização da didática, como método do pensamento e a forma de organização escolar, seria realizada com base na prática da escola, no sentido de encontrar as contradições reais em seus respectivos níveis e, também, em cada momento histórico, visualizar formas de luta e/ou superação das mesmas em cada realidade específica. Daí suas características de permanente construção baseada na dinâmica das relações sociais e seus conflitos.

Diante disso, entendemos que as mediações exigidas no contexto pedagógico são bastante complexas e a didática apresentase como importante espaço, no sentido de possibilitar aos sujeitos envolvidos no processo de conhecimento (alunos e professores), a compreensão dos aspectos contraditórios que se apresentam na realidade social e que se refletem na produção do conhecimento. A didática da EF não foge desse compromisso, já que a área da EF faz

Movimento, Porto Alegre, v. 13, n. 03, p. 181-199, setembro/dezembro de 2007. 
parte do contexto escolar, enquanto disciplina curricular. Para isso, surge a necessidade da área da EF ter claro qual é a sua especificidade no contexto escolar, para, então, poder avançar nos processos didáticos rumo à apropriação dos inúmeros determinantes sócio-históricos que constituem o nosso campo de conhecimento.

Sendo assim, faremos uma discussão sobre a identidade/especificidade da $\mathrm{EF}$, no sentido de melhor fundamentar a produção de conhecimento na área, como, também, situá-la no contexto da organização escolar.

Usaremos como obra básica para discutir essa questão, o livro intitulado Educação Física \& Ciência: Cenas de um casamento (in)feliz, de autoria do Prof. Dr. Valter Bracht. A referida publicação data o ano de 1999 e reúne os trabalhos do autor produzidos entre 1991 e 1996 sobre o tema EF e ciência.

Bracht (1999) conclui que, hoje, as posições sobre a identidade epistemológica da EF, na discussão brasileira, podem ser resumidas e classificadas em dois grandes grupos:

a) aqueles que entendem que a própria $\mathrm{EF}$ é uma ciência ou que no seu âmbito se construiu uma nova ciência, denominada, às vezes, de ciência da Motricidade Humana e outras de Ciência do Movimento Humano, ou ainda Cinesiologia e também Ciência do Esporte;

b) aqueles que a entendem como uma prática social de intervenção imediata e que enquanto prática humana necessita ser teoricamente elaborada.

No primeiro grupo, a legitimidade da EF somente seria alcançada quando reconhecida como ciência e aborda, especificamente, neste grupo, a tese da Ciência da Motricidade Humana $(\mathrm{CMH})$ do filósofo português Manoel Sérgio Vieira da Cunha.

No segundo grupo, Bracht (1999) situa-se e vê a EF como uma prática pedagógica e entende que, enquanto tal, requer um corpo de conhecimento que a sustente e, para isso, defende a idéia de que a EF não é uma ciência, mas está interessada na ciência e

Movimento, Porto Alegre, v. 13, n. 03, p. 181-199, setembro/dezembro de 2007. 
nas suas especificações. Para o autor, a EF é uma prática pedagógica, constituindo-se então, em uma prática de intervenção imediata e diz que reconhecer a EF primeiro enquanto prática pedagógica é fundamental para o reconhecimento do tipo de conhecimento, de saber necessário para orientá-la e para o reconhecimento do tipo de relação possível/desejável entre EF e o saber científico, ou as disciplinas científicas.

Sendo a EF uma prática de intervenção, para o referido autor, o que a caracteriza é a intenção pedagógica com que trata um conteúdo que é configurado e retirado do universo da cultura corporal de movimento.

Com esta posição, Bracht (1999) fundamenta a sua tese contra a formação da $\mathrm{CMH}$, especificamente a tentativa do filósofo Manoel Sérgio em querer tornar o movimento humano objeto de estudo de uma ciência. Para Bracht (1999, p. 32), neste âmbito, ocorre um equívoco que denomina "[...] uma concepção empirista ingênua de ciência" e refere-se ao fato da confusão estabelecida entre objeto científico e algum fato/fenômeno ou recorte da realidade. "O movimento humano por si só não é um objeto científico, são antes os problemas que lhes são colocados sob uma nova perspectiva que podem configurar um novo campo do conhecimento" (BRACHT, 1999, p. 32).

Portanto, retirado do universo da cultura corporal de movimento, o autor configura o objeto de estudo da $\mathrm{EF}$, de maneira mais abstrata, enquanto sendo a cultura corporal de movimento, pois entende que a EF, com o objetivo de fundamentar sua prática, está interessada nas explicações, compreensões e interpretações sobre as objetivações culturais do movimento humano fornecidas pela ciência. Nesta discussão, Bracht (1999) esclarece que a definição do objeto da EF está relacionada com a função social ou o papel social a ele atribuído. A função social define o tipo de conhecimento buscado para a sua fundamentação. Assim, este, por sua vez, determina a função atribuída à EF.

Para Bracht (1999), o objeto de uma prática pedagógica, é uma

Movimento, Porto Alegre, v. 13, n. 03, p. 181-199, setembro/dezembro de 2007. 
construção histórica e social em que os pressupostos teóricos são fundantes. "Não é possível dissociar o fenômeno do discurso da teoria que o constrói enquanto objeto (pedagógico)" (BRACHT, 1999, p. 45). Sendo, então, a cultura corporal de movimento objeto da EF, o movimentar-se é compreendido "[...] como forma de comunicação com o mundo que é constituinte e construtora de cultura, mas também, possibilitada por ela" (BRACHT, 1999, p. 45), pois o que caracteriza o movimento enquanto humano "[...] é o sentido/significado do moverse, sentido/significado mediado simbolicamente e que o coloca no plano da cultura" (BRACHT, 1999, p. 45). ${ }^{1}$

Juntamente com esta discussão epistemológica, Bracht (1999, p. 145) defende a posição política de envidar esforços para o teorizar em $\mathrm{EF}$, do qual este está frente a vários desafios:

Dentre eles destacamos a necessidade de articular organicamente os conhecimentos produzidos acerca do movimentar-se humano pelas diferentes disciplinas científicas; articular o conhecimento da realidade com uma visão prospectiva da realidade, portanto, uma visão de homem, de mundo e sociedade - articular descrição com prescrição; articular o saber conceitual com o saber prático.

$\mathrm{O}$ autor, quando fala em teoria da $\mathrm{EF}$, não insiste na sua adjetivação enquanto teoria científica, pelo menos não nos parâmetros da ciência clássica/predominante, ao mesmo tempo em que deixa claro que não abandonou a pretensão de racionalidade para essa teoria, ao contrário, chama a atenção para a necessidade da elucidação do conceito de racionalidade científica no fazer discursivo e prático. Critica o debate epistemológico atual, que de um lado, indica a superação da razão científica predominante e de outro, apresenta um certo relativismo propenso a abandonar "[...] a pretensão da fundamentação racional da prática" (BRACHT, 1999, p. 144).

\footnotetext{
${ }^{1}$ Bracht (1999) chama a atenção para o fato de que o conceito de cultura pode ser definido e operacionalizado tanto em termos sociais como em termos politicamente conservadores e articula um conceito de cultura que se coadune com os pressupostos sócio-filosóficos da educação crítica.

Movimento, Porto Alegre, v. 13, n. 03, p. 181-199, setembro/dezembro de 2007.
} 
Referente à tese que defende o relativismo científico em abdicação ao universalismo científico da modernidade, questiona se esse também não é "[...] um fundamento com pretensão universal?" (BRACHT, 1999, p. 142).

Neste debate epistemológico presente na EF e discutido principalmente por Bracht (1999), qual é então a nossa posição e qual a importância dessa posição em um trabalho que discute a didática da EF?

Concordamos com o autor quando este se posiciona contra a tese de que a EF somente alcançaria legitimidade afirmando-se como ciência, até mesmo porque, como já esclarecemos, a tese da EF tornar-se ciência não se fundamenta epistemologicamente pelo fato dos conhecimentos da área serem produzidos por múltiplas disciplinas científicas e direcionados por diferentes tipos de conhecimentos, conduzindo-a a diferentes análises e entendimentos mesmo que o objeto de estudo seja o mesmo.

Concordamos, também, juntamente com o autor, que a $\mathrm{EF}$ constitui-se como uma prática social, com caráter pedagógico e, como tal, não trata de qualquer movimento e sim do movimento humano enquanto cultura corporal ${ }^{2}$ que tem seu saber acumulado pela história dos sujeitos sociais em movimento. No momento em que entendemos o movimento como objeto de estudo da $\mathrm{EF}$, corremos o risco de atribuir à área a função de tratar de qualquer movimento. Isso fica claro quando, na escola, muitas vezes, atividades alternativas que requerem o espaço do pátio ou que envolvem qualquer forma de movimento como, por exemplo, limpar o pátio da escola, ensaio de apresentações para ocasiões festivas, hora cívica, etc., são desenvolvidas no horário das aulas de EF, demonstrando a falta de entendimento e a confusão que se estabelece quanto ao papel da EF na escola e a sua relação com o movimento humano. Ao nosso

\footnotetext{
2 Utilizamos o termo Cultura Corporal, conforme Coletivo de Autores (1992), no sentido de expressar a ampla e riquíssima produção de práticas expressivo-comunicativas que se externalizam pela expressão corporal e que constituem o âmbito do saber da EF escolar. Entendemos não ser necessário trazer a discussão que envolve esta denominação. Apenas queremos salientar que a expressão cultura corporal recebe algumas críticas de autores como Kunz e Bracht que denominam o âmbito do saber da EF de cultura de movimento e cultura corporal de movimento, respectivamente.
}

Movimento, Porto Alegre, v. 13, n. 03, p. 181-199, setembro/dezembro de 2007. 
ver, neste processo de desenvolvimento e compreensão do movimento nas aulas de EF, tira-se o compromisso pedagógico da área no que consiste em tematizar os elementos da cultura corporal, sistematizados no currículo escolar em forma de conteúdos (jogos, esportes coletivos e individuais, lutas, danças, etc.).

Com isso, queremos dizer que a EF, como atividade pedagógica vinculada à instituição escolar, tem sua especificidade de ensino cultura corporal - e o movimento humano, de uma forma geral, não deve ser exclusividade da EF e, sim, compromisso de toda a escola, devendo ser pensado por todo o trabalho escolar para evitarmos a dualidade existente entre atividades corporais e atividades cognitivas, onde o movimento é considerado um problema, sinônimo de indisciplina, desatenção e falta de interesse. Essa abordagem de movimento predominante na escola conduz ao entendimento de que o movimento é algo que deve ser controlado para que ocorra o desenvolvimento do aspecto intelectual, legitimando a visão de que o espaço das aulas de EF consiste no espaço do "suar" cabendo ao espaço da sala de aula a tarefa do "pensar".

Tendo claro, então, o conhecimento específico de que trata a EF no contexto escolar, a pergunta que fazemos, portanto, é como a didática da EF tematiza os conteúdos como o jogo, o esporte, a dança, as lutas e outros que constituem o âmbito da cultura corporal? Para responder a esse questionamento, concordamos com Bracht (1999) quanto à necessidade da EF ter um suporte teórico que deixe claro a sua concepção de razão científica, já que os pressupostos teóricos são fundados nos problemas relativos à prática concreta.

Diante do momento histórico em que vivemos, no qual se anuncia a crise da racionalidade, acreditamos ser necessário uma teoria de conhecimento, que contemple em seu interior, um saber científico que se contraponha ao saber científico técnico/formal da ciência moderna que nos domina, como também, ao saber procedente do movimento pós-moderno que em abdicação à supremacia do pensar e do fazer como única forma de produzir conhecimento e resolver problemas, associa-se à alegre aceitação do imediato, valorizando a crença e o senso comum.

Movimento, Porto Alegre, v. 13, n. 03, p. 181-199, setembro/dezembro de 2007. 
Para tanto, passaremos a discutir a relação da didática com a lógica de apropriação do conhecimento, pois como nos declara Wachowics apud Freitas (2000, p. 50):

Há vários métodos de ensino determinados pelo seu objeto, mas há uma lógica que comanda a apreensão da realidade pela inteligência, lógica essa que vai determinar a forma pela qual se dá a mediatização do saber.

\section{A LÓGICA FORMAL DE APREENSÃO DO SABER NO PROCESSO DIDÁTICO DA EDUCAÇÃO FÍSICA}

Kopnin (1978), na discussão sobre o método do conhecimento, escreve que a desintegração da natureza em partes isoladas, a divisão de processos e objetivos da natureza em classes determinadas, constituem a condição fundamental para os êxitos alcançados no campo do conhecimento da natureza. Contudo, este campo de conhecimento, ao mesmo tempo, nos legou a prática de analisar as coisas e processos em seu isolamento, fora da relação geral que existe entre eles, em um estado de imobilidade, eternamente imutável.

O autor declara que a ciência clássica reduz o método filosófico de conhecimento científico a três momentos: indução, dedução e verificação da teoria no experimento, onde a indução conduz à construção teórica, a dedução permite conseguir o efeito da teoria e o experimento verifica esses efeitos. Neste aspecto, a lógica do pensamento consiste num ciclo, indução-dedução-verificação, que se repete.

Porém, o método, enquanto um meio de obtenção de determinados resultados no conhecimento, reflete as leis do mundo objetivo sob a ótica do procedimento que o sujeito deve adotar para obter novos resultados. O método científico passa a ser a regularidade interna do movimento do pensamento humano, tomado como reflexo subjetivo do mundo objetivo, ou, o que é a mesma coisa, como lei objetiva transplantada e transferida na consciência humana, empregada de modo consciente e planificado como veículo de explicação e mudança do mundo.

Movimento, Porto Alegre, v. 13, n. 03, p. 181-199, setembro/dezembro de 2007. 
Por isso, o dispositivo formal do pensamento, elaborado através da lógica formal, torna-se incapaz de explicar o desenvolvimento do conhecimento científico, pois o pensamento racional, nesse processo de análise é capaz de relacionar objetividade com imobilidade, absolutividade com imutabilidade, mas não é capaz de alcançar a relação da objetividade do conhecimento com o seu desenvolvimento.

Kopnin (1978, p. 101), através da história do desenvolvimento do método filosófico, demonstra que os objetivos dos filósofos dos séculos XVII e XVIII consistia em dominar a natureza e, nesse processo, fazer descobertas científicas: "A filosofia da Idade Moderna mostrou nitidamente que sem método é impossível resolver a tarefa de aprender a natureza e dominar as suas forças espontâneas".

Dessa forma, no processo de conhecimento da ciência moderna, marcado pelo conhecimento desenvolvido por Galileu, Bacon, Descartes, Newton, entre outros, os cientistas naturais conquistam direitos exclusivos, pelo fato do conhecimento desenvolvido pelas ciências naturais apresentar-se dotado de sentido que viria a dar conta da palavra de ordem: o progresso. Nesse processo, as ciências sociais também estabelecem, através da teoria positivista, uma leitura de realidade ancorada no parâmetro das ciências naturais.

O conhecimento, portanto, por meio da estrutura lógica: suposição, derivação e verificação, absolutiza-se, por ser construído de forma linear e progressiva e com ele a razão toma a dimensão da exatidão.

Não alheio a este quadro apresentado no contexto moderno, "[...] a produção do conhecimento em Educação Física/Ciências do Esporte, segue o modelo de racionalidade científica moderna" (SILVA, 1990, p. 47).

A racionalidade científica tornou-se a forma hegemônica a ser considerada no âmbito da dimensão humana. Ser racional na área da EF consiste em fazer uso desta razão, assegurando seus pressupostos a fim de garantir, também, um lugar junto à humanidade, sendo assim, a EF curva-se diante da lógica racional dominante.

A cientificidade proposta para a EF, passou, sobretudo, a ser apreendida no âmbito da EF escolar, que assumiu os princípios da modernidade como a competição, o rendimento e a racionalidade técnica.

Movimento, Porto Alegre, v. 13, n. 03, p. 181-199, setembro/dezembro de 2007. 
Assim, no âmbito da EF escolar, através de uma abordagem "naturalística da história", ${ }^{3}$ expressão humana e leis naturais coincidem. Ou nas palavras de Kunz (1991, p. 163):

O movimento Humano nas chamadas Ciências do Esporte ou Educação Física tem recebido sempre uma interpretação baseada nas ciências naturais, ou seja: tem sido interpretado como um fenômeno físico que pode ser reconhecido e esclarecido de forma muito simples e objetiva, independente, inclusive, do próprio ser humano que o realiza $[\ldots]$. O movimento humano nada mais é do que o deslocamento do corpo ou de parte deste em tempo e espaço determinado.

Nessa lógica, sob a associação causa-efeito, estímulo-resposta, o comportamento humano é explicado na sua aparência externa. Esse processo, ao nosso ver, caracteriza-se pelo imediatismo, típico do movimento filosófico empirista que foi a base do desenvolvimento da ciência moderna, onde a aprendizagem, sob o processo metodológico da experimentação, surge como conseqüência da influência direta dos estímulos externos sobre os alunos.

A didática que desenvolve esse processo, ao nosso ver, constituise como conservadora, porque tem, enquanto base, uma concepção científica na qual a verdade transformou-se em pragmatismo, considerando como legítimo somente o conhecimento científico desenvolvido conforme o paradigma das ciências naturais, que, no seu processo de conhecimento, ofuscou o saber crítico.

Essa prática pedagógica torna-se limitada no que condiz ao entendimento e ao desenvolvimento de práticas sociais mais amplas da vida social, já que os sujeitos envolvidos no processo de ensino assumem a postura de seres funcionalistas-pragmáticos que desconsideram as dimensões histórico-culturais do mundo social. Sob a possibilidade da razão técnica, construímos uma visão naturalizada das coisas, e dentro dela a EF ganha um valor educacional simplista,

\footnotetext{
${ }^{3}$ Expressão usada por Engels (2000, p. 172) em Dialética da natureza, no sentido de fundamentar o entendimento dado ao processo social tendo como referencia os aspectos das leis naturais.
}

Mvimento, Porto Alegre, v. 13, n. 03, p. 181-199, setembro/dezembro de 2007. 
tornando-se incapaz de ser elemento mediador de uma visão crítica do mundo.

Como, então, através da construção do conhecimento no âmbito da didática da $\mathrm{EF}$, podemos possibilitar um processo de apreensão do saber, capaz de alcançar a relação da objetividade do conhecimento com o seu desenvolvimento (KOPNIN, 1978), no sentido de superar a visão pragmática e naturalizada das coisas?

\title{
4 A LÓGICA DIALÉTICA DE APREENSÃO DO SABER NO PROCESSO DIDÁTICO DA EDUCAÇÃO FÍSICA
}

Ao contrário de um entendimento de relações sociais de acordo com leis equivalentes àquelas que direcionam a natureza numa relação de causalidade entre as coisas, acreditamos que a história da humanidade é um processo sócio-cultural, e para tal compreensão surge a necessidade da concepção dialética entre o sujeito e o objeto no processo da atividade prática do homem. Para tanto, Kopnin (1978), refere-se à dialética materialista, tal como preconizou Marx em $O$ Capital, pois sendo a lógica o movimento do pensamento, a ciência contemporânea necessita de uma lógica que revele o conhecimento em seu desenvolvimento, enquanto processo de conhecimento da realidade pelo pensamento. Adialética do desenvolvimento da realidade consiste na lógica do pensamento combinado com a realidade.

Sobre esta questão, Lênin apud Kopnin (1978, p. 52), escreveu:

\begin{abstract}
$\mathrm{Na}$ teoria do conhecimento, como em todos os outros campos da ciência, deve-se raciocinar dialeticamente, não supor que o nosso conhecimento é acabado e imutável, mas entender de que modo o conhecimento surge do desconhecimento, de que modo o conhecimento impreciso e incompleto se torna mais completo e mais preciso.
\end{abstract}

Para que o movimento do pensamento se realize dialeticamente, devemos considerar, entre outras categorias, o par dialético do abstrato e do concreto.

Movimento, Porto Alegre, v. 13, n. 03, p. 181-199, setembro/dezembro de 2007. 
Para Kopnin (1978), a dialética materialista considera o concreto o ponto de partida e de chegada do conhecimento. O conhecimento não passa de maneira direta do sensorial-concreto ao concreto no pensamento. Esse caminho é complexo e contraditório. Para atingir o concreto autêntico, o conhecimento passa ao seu próprio oposto, ao abstrato, que, neste processo, constitui-se em um passo atrás, necessário, ao sucessivo avanço do conhecimento. Por um lado, o pensamento abstrato está mais distanciado do objeto, pois se vincula a ele através das sensações, percepções e noções. Por outro lado, está mais próximo dele por aprender a essência e as leis do movimento do fenômeno do mundo objetivo. Através da abstração se aprendem os mais profundos processos da natureza e da vida.

O autor explica que, se o pensamento se encerra em abstração, deixa de ser meio de conhecimento da realidade. A essência da abstração não consiste em apenas separar e isolar os indícios sensorialmente perceptivos. O pensamento teórico somente se conclui com o conhecimento concreto do objeto, um conhecimento novo, mais elevado. A princípio, o pensamento teórico se afasta do concreto (a noção plena "evapora" até atingir o grau de definição abstrata), depois torna a remontar, precisamente remontar e não simplesmente retornar a ele, pois se cria um novo concreto.

Kopnin (1978) escreve que o movimento do conhecimento sensorial-concreto, através do abstrato ao concreto, que reproduz o objeto no conjunto de abstrações é uma manifestação da lei da negação da negação. O abstrato é a negação do sensorial-concreto. $\mathrm{O}$ concreto no pensamento é a negação do abstrato. $\mathrm{O}$ concreto no pensamento não é a retomada do concreto inicial, mas o resultado da ascensão a um concreto novo, mais substancial.

Quando nos propomos, então, a abordar, dialeticamente, o âmbito do conhecimento da $\mathrm{EF}$, este é entendido, vinculado a todo o contexto social que o determina e é por ele determinado. Torna-se necessário, então, superar o caminho da abstração empírica ou mera reflexão que parte do particular para o universal ou do universal para o particular tal, como preconizam os pressupostos pautados pelos princípios das ciências naturais, e seguir um caminho que possibilite desvendá-lo em sua essência, do e para o concreto.

Movimento, Porto Alegre, v. 13, n. 03, p. 181-199, setembro/dezembro de 2007. 
Para tanto, ao nosso ver, compete à EF:

1) Entender o conhecimento do âmbito da cultura corporal, relacionado com o seu desenvolvimento. Isso passa pela compreensão da relação dialética, histórica e sem fim das apropriações e objetivações do gênero humano, no qual se encontra a prática social da cultura corporal, que, desde os tempos primitivos, acompanha os homens e as mulheres no seu processo de tornarem-se humanos. As posturas corporais, juntamente com as posturas morais e valorativas, ao longo da história, constituem o ser humano em verdadeiramente humano, dotado de cultura. À medida que a prática social humana foi tornandose complexa, resultante dos desafios postos na relação sujeito e natureza, as atividades corporais aperfeiçoaram-se, tornando-se, também, atividades produtoras e produtivas da história da humanidade.

Resultante da construção histórica da nossa corporeidade, Escobar (1997), fundamentada em Coletivo de Autores (1992, p. 63), declara que, hoje, dispomos de um valioso acervo de atividades expressivo-comunicativas com sentidos e significados lúdicos, estéticos, místicos e agonísticos como os jogos, a ginástica, a dança a mímica, etc. "Deve-se reconhecer, no entanto, que elas não indicam que o homem nasceu saltando, arremessando, jogando. Estas atividades foram construídas em certas épocas históricas como resposta a determinadas necessidades humanas".

2) Entender dialeticamente a EF enquanto área de conhecimento, que trata da cultura corporal, implica entender a ciência enquanto parte real da história natural e da história humana, pois para a construção de uma orientação didática nos parâmetros da lógica dialética, faz-se necessário, que as dimensões científicas que envolvem as práticas corporais (ciências do esporte) sejam entendidas como elementos integrais fundantes e fundados do e no processo de elaboração do mundo natural e social.

Tomada nessa perspectiva, a prática no contexto da didática da EF assume o compromisso, com a possibilidade de tratar os conteúdos da EF como objetivações culturais do movimento humano, produtos da relação de conhecimentos elaborados a partir das ciências

Movimento, Porto Alegre, v. 13, n. 03, p. 181-199, setembro/dezembro de 2007. 
biológicas e das ciências sociais e humanas. Como tal, entender a sua concretude, exige tomarmos as diferentes áreas de saberes científicos (ciências do esporte) que o sustentam (fisiologia, biomecânica, psicologia, sociologia, etc.) sob um teorizar pedagógico dialeticamente construido.

3) Elevar os aspectos técnico e valorativo das práticas corporais à compreensão de produção cultural. Neste caso, o entendimento de técnica não deverá restringir-se à simples prática motora e sim enquanto conhecimento elaborado no processo de desenvolvimento humano, científico e tecnológico. A apropriação da técnica, nesse sentido, significa o domínio do instrumental teórico-prático que os homens e as mulheres produziram na caminhada civilizatória para entender e transformar a natureza, a história, a sociedade e a si mesmos.

Para finalizar, no que se refere à compreensão das constantes variáveis dos fenômenos humanos ocorridos no contexto escolar de que Freitas (2000) nos fala, podemos dizer que o âmbito da didática da EF, no seu processo de trato com o conhecimento, deve incluir a realidade que se apresenta para além da sala de aula, do pátio ou dos muros da escola, mantendo-se sempre em alerta crítico, no sentido de perceber os aspectos sociais em que se encontra, atrelado às mudanças históricas.

O sistema capitalista, com o fim de superar este momento de crise e manter-se inquestionável, está construindo, através de bases teóricas (sociológicas, filosóficas e científicas) a idéia de que estamos vivendo em uma nova sociedade, com outra ordem e base, onde cabe aos homens e mulheres, em situações particulares, construirem alternativas de sobrevivência. Com esse pensamento, torna-se possível, com mais facilidade, ocultar as diretas implicações que a base econômica capitalista está realizando neste momento.

Freitas (2000) nos chama a atenção para o fato de que enquanto discutimos a "era da incerteza", o capital exerce a certeza através dos planos estratégicos das grandes multinacionais e através da economia de horas de trabalho com a introdução de novas tecnologias. A contemporaneidade, para Freitas (2000, p. 124), não

Movimento, Porto Alegre, v. 13, n. 03, p. 181-199, setembro/dezembro de 2007. 
significa a chegada de progresso social, e sim o Capitalismo cumprindo sua função histórica de revolucionar as forças produtivas. "Não há nada de novo na 'contemporaneidade' ou na 'pós-modernidade', exceto a forma de exploração e suas conseqüências culturais. A essência é a mesma".

Portanto, é neste momento complexo e particular, em que somos marcados pela contradição, que percebemos a importância do resgate da produção marxista, no sentido de explorar o seu caráter científico a fim de usá-lo como ferramenta para compreender a essência do movimento e do desenvolvimento dos aspectos sócio-históricos que se apresentam na realidade. Concordamos com Saviani apud Pereira (2003, p. 168), em discussão muito oportuna para os anos 90, quando diz:

Costumo dizer que é preciso que consideremos mais seriamente a afirmação de Sartre - que não era marxista - segundo a qual o marxismo é a filosofia viva e insuperável de nossos tempos. Considera ele que "um argumento antimarxista" não é mais que o rejuvenescimento aparente de uma idéia prémarxista. Uma pretensa "superação" do marxismo não será, no pior dos casos, mais que uma volta ao pré-marxismo e, no melhor, a redescoberta de um pensamento já contido na idéia que se acredita superar (SARTRE, 1963, p. 18). Esta idéia de Sartre se ancora na consideração de que uma filosofia é viva enquanto expressa a problemática própria da época que a suscitou é e insuperável enquanto o momento histórico de que é expressão não tiver sido superado. Ora, os problemas postos pelo marxismo são os problemas fundamentais da sociedade capitalista e enquanto estes problemas não forem resolvidos/superados não se pode falar que o marxismo terá sido superado.

Movimento, Porto Alegre, v. 13, n. 03, p. 181-199, setembro/dezembro de 2007. 


\begin{abstract}
Didactics of the pertaining to school physical education and the logical process of apprehension it to know

Abstract: This text aims at to point out, in the pertaining to school context, the knowledge that deals with the scope of the didactics of the Physical Education, demonstrating its relation with the formal logic of apprehension of knowing. For the overcoming of this reality, where the Physical Education is committed, in dominant way, with one practical one of competitive matrix, we present the logical dialectic as apprehension possibility, in the plan it thought, it present contradictory movement in the social reality and consequently, gift in the pertaining to school organization and the development corporal practical them.
\end{abstract}

Keywords: Didactics. Logic. Physical Education.

Didáctica del referente a la educación física
de la escuela y al proceso lógico de la
aprehensión del saber
Resumen: Este texto tiene como objetivo para
precisar, en referente a contexto de la escuela, el
conocimiento que se ocupa del alcance de la
didáctica de la educación física, demostrando su
relación con la lógica formal de la aprehensión de
saber. Para la superación de esta realidad, donde
la educación física está confiada, de manera
dominante, con un una práctica de la matriz
competitiva, presentamos la dialéctica lógica
como posibilidad de la aprehensión, en el plan
él pensamiento, él movimiento contradictorio del
presente en la realidad social y por lo tanto, el
regalo en referente a la organización de la escuela
y el práctico corporal del desarrollo ellos.
Palabras clave: Didáctica. Lógica. Educación Física.

\title{
REFERÊNCIAS
}

BRACHT, V. Educação Física e Ciência: Cenas de um casamento (in)feliz. ljuí: UNIJUÍ, 1999.

COLETIVO DE AUTORES. Metodologia do Ensino da Educação Física. São Paulo: Cortez, 1992.

ENGELS, F. Dialética da natureza. Rio de Janeiro: Paz e terra, 1979.

Movimento, Porto Alegre, v. 13, n. 03, p. 181-199, setembro/dezembro de 2007. 
ESCOBAR, M. O. Transformação da Didática: construção da teoria pedagógica como categorias da prática pedagógica: experiência na disciplina escolar Educação Física. 1997. Tese (Doutorado) - UNICAMP, Campinas, 1997.

FREITAS, L. C. Crítica da organização do trabalho pedagógico e da didática. Campinas: Papirus, 2000.

KOPNIN, P. V. A Dialética como Lógica e Teoria do Conhecimento. Rio de Janeiro: Civilização Brasileira, 1978.

KUNZ, E. Educação Física: Ensino e Mudança. ljuí: UNIJUÍ, 1991.

KUNZ, E. Transformação didático-pedagógica do Esporte. ljuí: UNIJUÍ, 1994.

PEREIRA, M. de F. R. Concepções teóricas da pesquisa em educação: superando dificuldades. In: LOMBARDI, J. C. (Org.). Globalização, pós-modernidade e educação: história, filosofia e temas transversais. Campinas, SP: Autores Associados, 2003

SILVA, R. V. S. Mestrados em Educação no Brasil: pesquisando suas pesquisas. 1990. Dissertação (Mestrado). UFSM, Santa Maria, 1990.

WACHOWICS, L. A. O método dialético na didática. Campinas: Papirus, 1989.

Movimento, Porto Alegre, v. 13, n. 03, p. 181-199, setembro/dezembro de 2007. 